\title{
Transactions
}

Cite this: Dalton Trans., 2012, 41, 1441

\section{Paramagnetic dithiolene complexes as metallo-ligands: ether/thioether coordination $\uparrow$}

\author{
Alessia Famengo, ${ }^{a, b}$ Dalice Pinero, ${ }^{a}$ Olivier Jeannin, ${ }^{* a}$ Thierry Guizouarn ${ }^{a}$ and Marc Fourmigué $* a$ \\ Received 25th October 2011, Accepted 15th November 2011 \\ DOI: $10.1039 / \mathrm{cldt12028j}$
}

The secondary coordination ability of a paramagnetic nickel dithiolene complex, bearing an ether coordinating function within a nine-membered flexible ring, has been demonstrated in its $\left[\mathrm{NiCl}(\mathrm{DMF})_{2}\right]^{+}$complex, through coordination by both ether and thioether functions, allowing for a ferromagnetic interaction between both paramagnetic entities.

Paramagnetic metal dithiolene complexes ${ }^{1}$ afford a wide variety of structures with associated conducting and magnetic properties. ${ }^{2}$ The most common magnetic species are, either the $\mathrm{d}^{9}\left(S=\frac{1}{2}\right)$ $\left.[\mathrm{Cu} \text { (dithiolene })_{2}\right]^{2-}$ copper complexes, or the oxidized, formally $\mathrm{d}^{7}$ $\left(S=\frac{1}{2}\right)\left[\mathrm{M}(\text { dithiolene })_{2}\right]^{1-}(\mathrm{M}=\mathrm{Ni}, \mathrm{Pd}, \mathrm{Pt})$ anionic complexes, ${ }^{2,3}$ and the gold neutral complexes $\left[\mathrm{Au}(\text { dithiolene })_{2}\right]^{\circ}{ }^{4}$ The magnetic properties of these salts are essentially controlled by the overlap interactions between radical species, from weak interactions favoring localized magnetic states within dimers or spin chains, ${ }^{5}$ to stronger interactions allowing for metallic conductivity. ${ }^{2,4 a}$

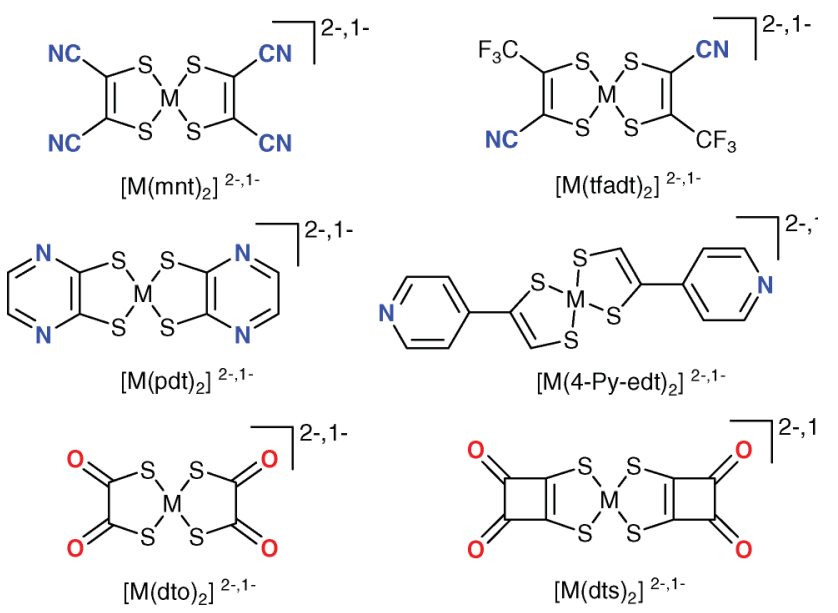

Besides, as recently reviewed, ${ }^{6}$ paramagnetic dithiolene complexes can also be considered as metallo-ligand toward

${ }^{a}$ Sciences Chimiques de Rennes, Université Rennes 1, CNRS UMR 6226, Campus de Beaulieu, 35042 Rennes, France.E-mail: marc.fourmigue@univrennes1.fr, olivier.jeannin@univ-rennes1.fr

${ }^{b}$ Dipartimento di Scienze Chimiche, Università degli Studi di Padova, via Marzolo 1, 35131 Padova, Italy

$\dagger$ Electronic supplementary information (ESI) available: Synthetic details and cif files for the four structures. CCDC reference numbers 850836 850839. For ESI and crystallographic data in CIF or other electronic format see DOI: $10.1039 / \mathrm{cldt} 12028 \mathrm{j}$ other metallic centres for the elaboration of more complex architectures. ${ }^{7}$ For example, complexes such as $\left[\mathrm{M}(\mathrm{mnt})_{2}\right]^{2-1-}$ or $\left[\mathrm{M}(\mathrm{tfadt})_{2}\right]^{2-, 1-}$ form heterobimetallic chains through metalnitrogen coordination, ${ }^{3,8}$ with $\mathrm{Mn}^{\mathrm{III}}$ porphyrins, ${ }^{9}[\mathrm{Ni}(\text { cyclam })]^{2+},{ }^{10}$ or polymetallic ${ }^{11}$ complexes such as $\left[\mathrm{Mn}_{4}(\mathrm{hmp})_{6}\left(\mathrm{CH}_{3} \mathrm{CN}\right)_{2}\right]^{4+}$ (hmp: 2-hydroxymethylpyridine).$^{12}$ Other examples of nitrogen coordination can be also found in fused pyrazine ${ }^{13}$ or in 4-pyridyl derivatives. ${ }^{14}$

On the other hand, complexes with oxygen-based coordinating functions are essentially limited to the chelating dithiooxalate (dto) and dithiosquarate (dts) ligands. Because of the strongly electron-withdrawing nature of the carbonyl groups, both ligands only stabilize the most reduced dianionic forms of the dithiolene complexes, the diamagnetic $\left[\mathrm{Ni}(\mathrm{dto})_{2}\right]^{2-}$ or the paramagnetic $\mathrm{d}^{9}$ $\left(S=\frac{1}{2}\right)\left[\mathrm{Cu}(\mathrm{dto})_{2}\right]^{2-} \cdot{ }^{15}$ Looking for alternative substitution patterns that would allow the use of the monoanionic, formally $\mathrm{d}^{7}, S=\frac{1}{2}$ $\left.[\mathrm{Ni} \text { (dithiolene })_{2}\right]^{-}$complexes while keeping oxygen atoms for secondary coordination, we considered the unknown monoanionic nickel complex 1 where a $-\left(\mathrm{CH}_{2}\right)_{2}-\mathrm{O}-\left(\mathrm{CH}_{2}\right)_{2}-$ flexible moiety is directly linked to the outer sulfur atoms.
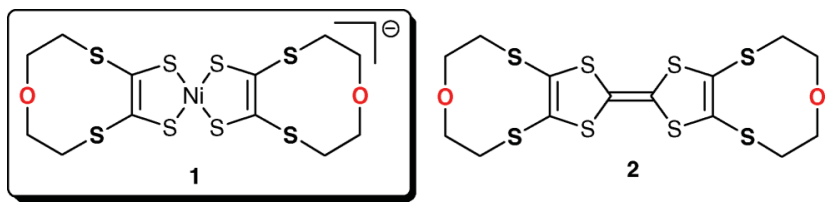

Such a complex can potentially coordinate extra metal cations through combined coordination of the ether and thioether functions, with the latter taking part to the spin density distribution of the dithiolene complex. Note that this coordination function has been considered on analogous tetrathiafulvalene derivatives such as 2 only for alkali cations, ${ }^{16,17}$ while coordination to paramagnetic metallic cations was never investigated.

We describe here the synthesis of the paramagnetic $\left(S=\frac{1}{2}\right)$ nickel complex 1, isolated as a tetrabutyl ammonium salt. Further reaction with nickel salts afforded a first example of coordination of 1 to an octahedral nickel dication through the combined ether and thioether moieties to afford a bimetallic $\left(S=1, S=\frac{1}{2}\right)$, complex demonstrating the potential of such dithiolene complexes to act as metalloligands.

The preparation of the nickel complex (Scheme 1) relies on the base opening of the dithiocarbonate $\mathbf{3 b},{ }^{18}$ obtained itself from the trithiocarbonate 3a. ${ }^{16,17}$ Addition of half equiv. of $\mathrm{NiCl}_{2}$, afforded directly (air oxidation) the monoanionic complex as a DMF 


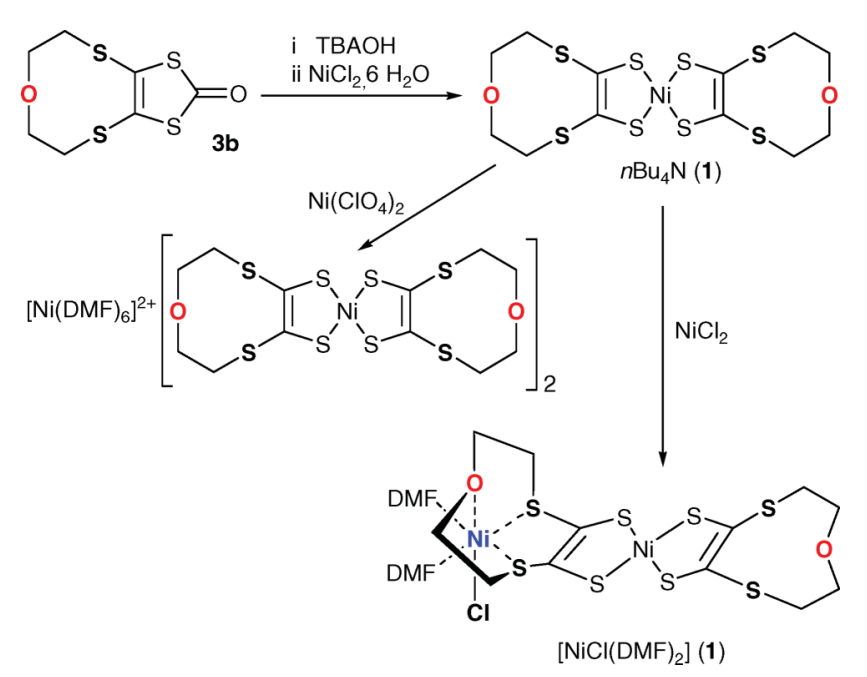

Scheme 1 Syntheses and structures of the complexes.

solvate, $\left(n \mathrm{Bu}_{4} \mathrm{~N}^{+}\right)\left(\mathbf{1}^{-\bullet}\right)$. DMF. It reduces reversibly to the dianion at $-0.66 \mathrm{~V} v s$. SCE, while it oxidizes reversibly to the neutral complex at $+0.32 \mathrm{~V}$ vs. SCE. Further irreversible oxidation to the cationic state is found at $1.16 \mathrm{~V}$ vs. SCE.

Note that during our attempts to coordinate $\mathbf{1}^{-\bullet}$ with $\mathrm{Fe}^{3+}$ salts, a few crystals of the oxidized neutral complex $\mathbf{1}^{0}$ were obtained instead, $\$$ allowing for a comparison of the intramolecular bond distances within the dithiolene core in the two redox states, $\mathbf{1}^{-\bullet}$ and $\mathbf{1}^{0}$.

Investigation of the secondary coordination of the $\mathbf{1}^{-\bullet}$ radical anions was performed with two $\mathrm{Ni}^{2+}$ different salts, $\mathrm{Ni}\left(\mathrm{ClO}_{4}\right)_{2}$ and $\mathrm{NiCl}_{2}$. With the former, an insoluble product was first obtained. Redissolution in $\mathrm{DMF}$ and $\mathrm{Et}_{2} \mathrm{O}$ layering afforded a bimetallic nickel salt, which analyzes as $\left[\mathrm{Ni}(\mathrm{DMF})_{6}\right](\mathbf{1})_{2}$, that is two radical anion complexes for one $\mathrm{Ni}^{2+}$ cation solvated with six DMF molecules. On the other hand, with $\mathrm{NiCl}_{2}$, another salt was obtained, which analyses as $\left[\mathrm{NiCl}(\mathrm{DMF})_{2}\right][\mathbf{1}] \cdot\left(2 \mathrm{DMF}, \mathrm{Et}_{2} \mathrm{O}\right)$, where direct coordination of the dithiolene complex to the outer $\mathrm{Ni}^{2+}$ species is actually observed.

The $\mathbf{1}^{-}$dithiolene complex in the two salts with $n \mathrm{Bu}_{4} \mathrm{~N}^{+}$and $\left[\mathrm{Ni}(\mathrm{DMF})_{6}\right]^{2+}$, as well as in its neutral state, adopts a common geometry of the nine-membered ring (Fig. 1), with the oxygen atom pointing toward the centre of the molecule. Comparison of the intramolecular bond distances with those found in the oxidized $\mathbf{1}^{0}$ (Table 1) shows the anticipated evolutions, with the shortening of the Ni-S and $\mathrm{S}-\mathrm{C}$ bonds, of antibonding character in the SOMO of such dithiolene radical anions, combined with the lengthening of the $\mathrm{C}=\mathrm{C}$ bond, associated with its bonding character in the dithiolene SOMO.

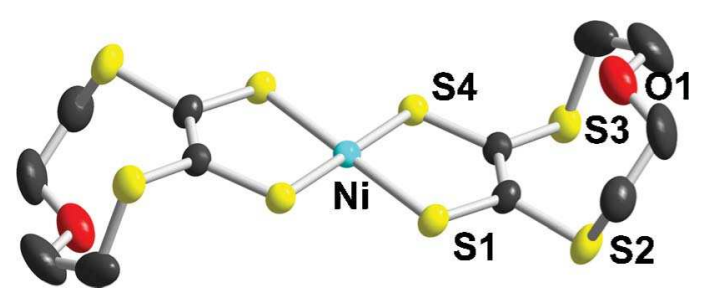

Fig. 1 Ortep view of the $\mathbf{1}^{-\bullet}$ radical anion in $\left(n \mathrm{Bu}_{4} \mathrm{~N}\right)(\mathbf{1}) \cdot \mathrm{DMF}$.
Table 1 Comparison of intramolecular bond lengths within the $\mathrm{NiS}_{2} \mathrm{C}_{2}$ metallacycle in $\mathbf{1}^{-}$in various salts and in $\mathbf{1}^{0}$

\begin{tabular}{lllll}
\hline Compound & Counter ion & $\mathrm{Ni}-\mathrm{S}(\AA)$ & $\mathrm{S}-\mathrm{C}(\AA)$ & $\mathrm{C}=\mathrm{C}(\AA)$ \\
\hline $\mathbf{1}^{-}$ & $n \mathrm{Bu}_{4} \mathrm{~N}^{+}$ & $2.1492(9)$ & $1.734(4)$ & $1.356(5)$ \\
& & $2.1500(8)$ & $1.742(3)$ & \\
$\mathbf{1}^{0}$ & & $2.1309(4)$ & $1.710(2)$ & $1.387(3)$ \\
$\mathbf{1}^{-}$ & & $2.1345(5)$ & $1.707(2)$ & \\
$\mathrm{Ni}(1)$ & $\mathrm{Ni}(\mathrm{DMF})_{6}{ }^{++}$ & $2.1511(7)$ & $1.733(3)$ & $1.356(4)$ \\
& & $2.1515(7)$ & $1.732(3)$ & \\
$\mathrm{Ni}(2)$ & & $2.1451(8)$ & $1.725(4)$ & $1.345(5)$ \\
$\mathbf{1}^{-}$ & & $2.1473(10)$ & $1.739(4)$ & \\
Coord. side & $\mathrm{NiCl}(\mathrm{DMF})_{2}{ }^{+}$ & $2.164(2)$ & $1.736(4)$ & $1.360(5)$ \\
Uncoord. side & & $2.149(2)$ & $1.741(4)$ & $1.363(5)$ \\
\hline
\end{tabular}

The temperature dependence of the magnetic susceptibility of $\left[\mathrm{Ni}(\mathrm{DMF})_{6}\right](\mathbf{1})_{2}$ (Fig. 2a) shows a Curie-Weiss type behavior, with a Curie constant of $2.00(1) \mathrm{K} \mathrm{cm}^{3} \mathrm{~mol}^{-1}$, (and $\theta=-0.33(1) \mathrm{K}$ ), corresponding to the contribution of two $\mathbf{1}^{-\bullet}$ radical anions $\left(S=\frac{1}{2}\right)$, without interaction with the $\left[\mathrm{Ni}(\mathrm{DMF})_{6}\right]^{2+}$ species in octahedral environment $(S=1)$. EPR determination of the $g$ value of $\mathbf{1}$ in its tetrabutyl ammonium salt gives $g_{1}=2.069$. It follows that the $g$ value for the $\left[\mathrm{Ni}(\mathrm{DMF})_{6}\right]^{2+}$ species amounts here to $g_{\mathrm{Ni}}=2.188$, a value comparable to that usually observed for $\mathrm{Ni}$ (II) centres in an octahedral coordination sphere. ${ }^{10}$

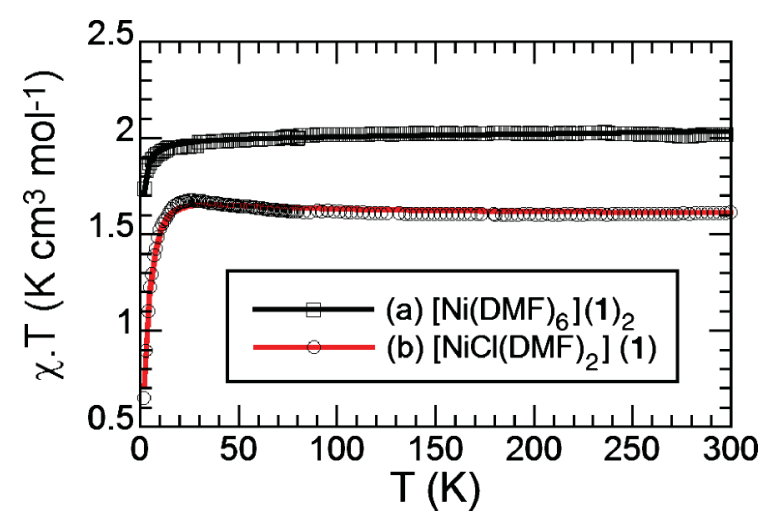

Fig. 2 Temperature dependence of the $\chi T$ product for (a) $\left[\mathrm{Ni}(\mathrm{DMF})_{6}\right](\mathbf{1})_{2}$ and (b) $\left.\mid \mathrm{NiCl}(\mathrm{DMF})_{2}\right](\mathbf{1})$.

When the $\mathbf{1}^{-\bullet}$ tetrabutyl ammonium salt was faced with $\mathrm{NiCl}_{2}$ rather than $\mathrm{Ni}\left(\mathrm{ClO}_{4}\right)_{2}$, another salt was obtained, which analyses as $\left[\mathrm{NiCl}(\mathrm{DMF})_{2}\right][\mathbf{1}] \cdot\left(2 \mathrm{DMF}, \mathrm{Et}_{2} \mathrm{O}\right)$. As shown in Fig. 3, a cationic $\left[\mathrm{NiCl}(\mathrm{DMF})_{2}\right]^{+}$moiety is now coordinated to the $\mathbf{1}^{-\bullet}$ radical anion, with the coordination sphere of the $\mathrm{NiCl}(\mathrm{DMF})_{2}{ }^{+}$cation completed by the two sulfur atoms and the oxygen atom of the dithiolene fragment.

This salt provides the first example of coordination of such ether/thioether substituted dithiolene complexes with paramagnetic cations. The $\mathrm{Ni}^{2+}$ cation is in an octahedral environment. Bond distances within the dithiolene metallacycles (Table 1) confirm the radical anion character, with a very weak disymmetrisation due to the $\mathrm{NiCl}^{+}$coordination. Note also that the recurrent conformation adopted by the flexible $-\left(\mathrm{CH}_{2}\right)_{2}-\mathrm{O}-\left(\mathrm{CH}_{2}\right)_{2}-$ arm in the other complexes (Fig. 1) is modified here to allow for the $\mathrm{Ni}^{2+}$ coordination with both the ether oxygen atom and the two thioether functions. Temperature dependence of $\chi T$ (Fig. 2b), 


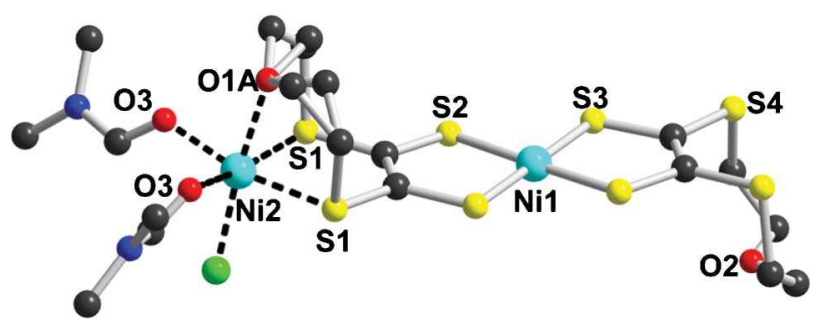

Fig. 3 Molecular structure of the $\left[\mathrm{NiCl}(\mathrm{DMF})_{2}\right][\mathbf{1}]$ moiety in its $\mathrm{DMF}$, $\mathrm{Et}_{2} \mathrm{O}$ solvate. Bond distances: Ni-Cl: 2.337(3), Ni-O3: 2.039(2), Ni-O1A: 2.169(4), Ni-S1: 2.399(2) A. The ethylene bridges are disordered on two positions; $\mathrm{H}$ atoms are omitted for clarity.

measured on a compressed polycrystalline sample, gives a room temperature value of $1.6 \mathrm{~K} \mathrm{~cm}^{3} \mathrm{~mol}^{-1}$, corresponding to the combined contributions of $\mathbf{1}^{-\bullet}\left(S=\frac{1}{2}\right)$ and octahedral $\mathrm{Ni}^{2+}(S=1$ with $\left.g_{\mathrm{Ni}}=2.19\right)$. The $\chi T$ product increases up to a maximum of 1.67 at $25 \mathrm{~K}$ before decreasing sharply, indicating the presence of a ferromagnetic interaction between the two centres. The isotropic interaction between $S=1$ and $S=\frac{1}{2}$ magnetic centres ${ }^{19,20}$ gives two $S=\frac{1}{2}$ and $S=3 / 2$ states, separated by $3 J / 2$ for an Hamiltonian that writes as $\mathbf{H}=-J \mathrm{~S}_{1} \cdot \mathrm{S}_{\mathrm{Ni}}$. The $g$ values for the corresponding doublet and quartet states write as $g_{1 / 2}=\left(4 g_{\mathrm{Ni}}-g_{1}\right) / 3$ and $g_{3 / 2}=\left(2 g_{\mathrm{Ni}}+g_{1}\right) / 3$ and an approximate expression of the magnetic susceptibility $\chi_{\mathrm{dim}}$ of such dimers is then given by: ${ }^{20}$

$$
\chi_{\mathrm{dim}}=\frac{N \beta^{2}}{4 k T} \frac{g_{1 / 2}^{2}+10 g_{3 / 2}^{2} \exp (3 J / 2 k T)}{1+2 \exp (3 J / 2 k T)}
$$

with here $g_{1 / 2}=2.23$ and $g_{3 / 2}=2.15$. In order to take also into account the decrease of susceptibility observed at lower temperatures, we have introduced a mean-field correction in the expression of the susceptibility, which writes as:

$$
\chi=\frac{\chi_{\text {dim }}}{1-\frac{z J^{\prime}}{N g^{2} \beta^{2}} \chi_{\text {dim }}}
$$

Best fit gives $J / k=+10 \mathrm{~cm}^{-1}$ and $J^{\prime}=-0.6 \mathrm{~cm}^{-1}(z=4)$ and demonstrates that the direct coordination of the paramagnetic $(S=1) \mathrm{NiCl}$ moiety through the combined ether and thioether functions allows for a sizeable ferromagnetic interaction with the dithiolene radical anion complex, through the coordination to its outer sulfur atoms. Note that this $S=3 / 2$ ground state expected from the ferromagnetic coupling of the $S=1$ and $S=1 / 2$ spin states of the Ni ion and the complex 1 should present a ZFS that could also explain the sharp decrease in the $\chi T$ plot at low temperatures.

We are currently investigating other cations and crystallization media in order to favor the formation of extended chains, where a central metal atom would adopt a similar octahedral coordination but formed by two such ether/bis(thioether) functions.

\section{Acknowledgements}

Financial support for this project was obtained from the ANR (Paris) under contract no. ANR-09-BLAN-0175-03. We thank L. Piekara-Sady (Poznan, Poland) for EPR measurements and one of the referees for useful comments on magnetic properties.

\section{Notes and references}

$\$\left(n \mathrm{Bu}_{4} \mathrm{~N}\right)(\mathbf{1})^{\cdot} \mathrm{DMF}: \mathrm{C}_{31} \mathrm{H}_{59} \mathrm{~N}_{2} \mathrm{NiO}_{3} \mathrm{~S}_{8}, M_{\mathrm{r}}=822.99$, monoclinic, $C 2 / c, a=$ 22.307(1), $b=12.9869(6), c=17.3369(8) \AA, \beta=125.516(2)^{\circ}, V=4088.1(3)$ $\AA^{3}, Z=4, D_{\mathrm{c}}=1.337 \mathrm{~g} \mathrm{~cm}^{-3}, T=150(2) \mathrm{K}$, with Mo-K $\alpha(\lambda=0.71073)$, 11158 reflections collected, 4634 unique $\left(R_{\text {int }}=0.0373\right), R_{1}[I>2 \sigma(I)]=$ $0.0531, \mathrm{w} R_{2}(F$, all data $)=0.1636, \mathrm{GoF}=1.071$.

$\left[\mathrm{Ni}(\mathrm{DMF})_{6}\right](\mathbf{1})_{2}: \mathrm{C}_{42} \mathrm{H}_{70} \mathrm{~N}_{6} \mathrm{Ni}_{3} \mathrm{O}_{10} \mathrm{~S}_{16}, M_{\mathrm{r}}=1508.23$, triclinic, $P \overline{1}, a=$ 8.9808(2), $b=13.5908(2), c=14.3025(3) \AA, \alpha=83.547(1), \beta=81.743(1)$, $\gamma=79.245(1)^{\circ}, V=1690.68(6) \AA^{3}, Z=1, D_{\mathrm{c}}=1.481 \mathrm{~g} \mathrm{~cm}^{-3}, T=150(2) \mathrm{K}$, with Mo-K $\alpha(\lambda=0.71073), 37140$ reflections collected, 7751 unique $\left(R_{\text {int }}=\right.$ $0.033), R_{1}[I>2 \sigma(I)]=0.0364, \mathrm{w} R_{2}(F$, all data $)=0.0993, \mathrm{GoF}=1.108$.

$\left[\mathrm{NiCl}(\mathrm{DMF})_{2}\right](\mathbf{1}): \mathrm{C}_{18} \mathrm{H}_{30} \mathrm{ClN}_{2} \mathrm{Ni}_{2} \mathrm{O}_{4} \mathrm{~S}_{8}, M_{\mathrm{r}}=747.79$, monoclinic, $C 2 / \mathrm{m}$, $a=13.9129(7), b=11.3753(5), c=25.6529(15) \AA, \beta=98.211(3)^{\circ}, V=$ 4018.3(4) $\AA^{3}, Z=4, D_{\mathrm{c}}=1.440 \mathrm{~g} \mathrm{~cm}^{-3}, T=150(2) \mathrm{K}$, with Mo-K $\alpha(\lambda=$ $0.71073), 12097$ reflections collected, 4740 unique $\left(R_{\text {int }}=0.0293\right), R_{1}[I>$ $2 \sigma(I)]=0.0482, \mathrm{w} R_{2}(F$, all data $)=0.1493, \mathrm{GoF}=1.045$.

$(1)^{0}: \mathrm{C}_{6} \mathrm{H}_{8} \mathrm{Ni}_{0.5} \mathrm{OS}_{4}, M_{\mathrm{r}}=253.72$, triclinic, $P \overline{1}, a=7.6821(6), b=8.1203(7)$, $c=8.7853(6) \AA, \alpha=97.483(3), \beta=114.055(3), \gamma=99.403(3)^{\circ}, V=481.79(6)$ $\AA^{3}, Z=2, D_{\mathrm{c}}=1.749 \mathrm{~g} \mathrm{~cm}^{-3}, T=150(2) \mathrm{K}$, with Mo-K $\alpha(\lambda=0.71073), 7481$ reflections collected, 2157 unique $\left(R_{\text {int }}=0.0309\right), R_{1}[I>2 \sigma(I)]=0.0251$, $\mathrm{w} R_{2}(F$, all data $)=0.0653, \mathrm{GoF}=1.038$

1 For recent reviews see: (a) Dithiolene Chemistry: Synthesis, Properties and Applications, ed. E. I. Stiefel, Prog. Inorg. Chem., vol. 52, John Wiley \& Sons, Hoboken, NJ, 2004; (b) A. Vlcek, Coord. Chem. Rev., 2010, 254(13-14), 1357.

2 R. Kato, Chem. Rev., 2004, 104, 5319.

3 N. Robertson and L. Cronin, Coord. Chem. Rev., 2002, 227, 93.

4 (a) N. Tenn, N. Bellec, O. Jeannin, L. Piekara-Sady, P. Auban-Senzier, J. Iniguez, E. Canadell and D. Lorcy, J. Am. Chem. Soc., 2009, 131, 16961; (b) O. J. Dautel, M. Fourmigué, E. Canadell and P. Auban-Senzier, $A d v$. Funct. Mater, 2002, 12, 693.

5 C. Faulmann and P. Cassoux, Prog. Inorg. Chem., 2003, 52, 399.

6 S. Rabaca and M. Almeida, Coord. Chem. Rev., 2010, 254, 1493.

7 E. Pardo, R. Ruiz-Garcia, J. Cano, X. Ottenwaelder, R. Lescouezec, Y. Journaux, F. Lloret and M. Julve, Dalton Trans., 2008, 2780.

8 O. Jeannin, J. Delaunay, F. Barrière and M. Fourmigué, Inorg. Chem., 2005, 44, 9763.

9 L. N. Dawe, L. Turnbow, J. M. Miglioi, M. L. Taliaferro, W. W. Shum, J. D. Bagnato, L. N. Zakharov, A. L. Rheingold, A. M. Arif, M. Fourmigué and J. S. Miller, Inorg. Chem., 2005, 44, 7530.

10 O. Jeannin, R. Clérac, T. Cauchy and M. Fourmigué, Inorg. Chem., 2008, 47, 10656.

11 A. M. Madalan, N. Avarvari, M. Fourmigué, R. Clérac, L. Chibotaru, S. Clima and M. Andruh, Inorg. Chem., 2008, 47, 940.

12 H. Hiraga, H. Miyasaka, K. Nakata, T. Kajiwara, S. Takaishi, Y. Oshima, H. Nojiri and M. Yamashita, Inorg. Chem., 2007, 46, 9661.

13 (a) Y. Kobayashi, B. Jacobs, M. D. Allendorf and J. R. Long, Chem. Mater, 2010, 22, 4120; (b) S. Takaishi, M. Hosoda, T. Kajiwara, H. Miyasaka, M. Yamashita, Y. Nakanishi, Y. Kitagawa, K. Yamaguchi, A. Kobayashi and H. Kitagawa, Inorg. Chem., 2009, 48, 9048.

14 (a) S. Rabaca, D. Belo, A. C. Cerdeira, S. I. G. Dias, M. B. C. Branco, L. C. J. Pereira, I. C. Santos, M. Fourmigué and M. Almeida, CrystEngComm, 2009, 11, 2154; (b) S. Rabaca, A. C. Cerdeira, A. I. S. Neves, S. I. G. Dias, C. Mézière, I. C. Santos, L. C. J. Pereira, M. Fourmigué, R. T. Henriques and M. Almeida, Polyhedron, 2009, 28, 1069.

15 (a) A. Gleizes and M. Verdaguer, J. Am. Chem. Soc., 1981, 103, 7373; (b) A. Gleizes and M. Verdaguer, J. Am. Chem. Soc., 1984, 106, 3727.

16 T. K. Hansen, T. Jørgensen, P. C. Stein and J. Becher, J. Org. Chem., 1992, 57, 6403.

17 T. K. Hansen, T. Jørgensen and J. Becher, J. Chem. Soc., Chem. Commun., 1992, 1550.

18 M. Wagner, R.-M. Olk and E. Hoyer, J. Prakt. Chem., 1994, 336, 177.

19 (a) I. Morgenstern-Badarau, M. Rerat, O. Kahn, J. Jaud and J. Galy, Inorg. Chem., 1982, 21, 3050; (b) S. Desjardins, I. Morgenstern-Badarau and O. Kahn, Inorg. Chem., 1984, 23, 3833; (c) Y. Journeaux, O. Kahn, I. Morgenstern-Badarau, J. Galy, J. Jaud, A. Bencini and D. Gatteschi, J. Am. Chem. Soc., 1985, 107, 6305.

20 O. Kahn, in Molecular Magnetism, Wiley-VCH, 1993, Ch. 6. 